Article

\title{
Understanding the Impact of Environmental Education on Tourists' Future Visit Intentions to Leisure Farms in Mountain Regions
}

\author{
Winitra Leelapattana ${ }^{1}{ }^{\circledR}$, Shih-Yun Hsu ${ }^{2}$, Weerapon Thongma ${ }^{1}$, Chun Chen ${ }^{3, *}$ \\ and Fu-Mei Chiang ${ }^{1}$ \\ 1 School of Tourism Development, Maejo University, Sansai, Chiang Mai 50290, Thailand; \\ w.leelapattana@gmail.com (W.L.); weerapon@mju.ac.th (W.T.); tc.farm@msa.hinet.net (F.-M.C.) \\ 2 Department of Leisure and Recreation Management, Asia University, Taichung 41354, Taiwan; \\ shsu1@asia.edu.tw \\ 3 Department of Tourism, Changzhou Institute of Industry Technology, Changzhou 213164, China \\ * Correspondence: chenchun@czili.edu.cn; Tel.: +86-051986335134
}

Received: 10 February 2019; Accepted: 12 March 2019; Published: 14 March 2019

\begin{abstract}
The research problem of this study is to understand whether people with higher level of EE are more likely to choose farm stays for their vacation. The main aim of this study is to investigate the causal relationship between an individual's environmental education (EE) and their theory of planned behavior (TPB) decision-making process that leads to future visit intention. A convenient sampling method was used to survey visitors of Toucheng Leisure Farm in the mountain region of Taiwan; and a total of 600 responses were collected. Structural equation modeling (SEM) was used to analyze the data. The results showed that five of the six hypotheses were supported. This finding suggests that environmental education makes an individual more pro-environmental and susceptible to the social norms about environmental protection. Environmental education, however, does not affect the inconvenience or extra cost incurred by purchasing green products.
\end{abstract}

Keywords: environmental education; behavioral intention; theory of planned behavior; leisure farm

\section{Introduction}

\subsection{Background}

Environmental issues are gradually becoming a global concern, but due to a series of difficulties, business entities are still reluctant to commit to greener operation [1]. There are financial concerns, inadequacy of environmental knowledge and skill, and uncertainty of outcome that contribute to the unwillingness of businesses to engage in greener management [2]. Meanwhile, the marketplace has shifted to demand greener products and services [3], which forces businesses to change and take actions [4]. Thus the issue of sustainable management has become an intriguing subject to both practitioners and academicians [5].

Theory of planned behavior (TPB), proposed by Ajzen [6], is designed to study an individual's decision-making process that leads to a particular behavioral intention. TPB is often used to study customers' decision to purchase a particular product or service. For example, TPB has been applied in lodging industry to study customers' willingness to stay in green hotels $[3,7,8]$. In general, TPB comprises three factors of determinants that affect an individual's behavioral intention. The first factor is attitude. The second factor of variables is subjective norm. The third factor is perceived behavioral control. TPB is, therefore, a popular research tool to study the decision-making process. TPB, however, has been criticized of overlooking the emotional element [3]. Therefore, additional components are 
often introduced to improve TPB's predictability [8]. For a green customer, an emotional concern for the environment is a strong reason for his/her actions. Thus, environmental components are added in this study to strengthen the model.

The study focuses on a farm stay called Toucheng Leisure Farm, which is located in the mountain regions in the northeast coast of Taiwan. The farm offers a wide range of activities based on rural atmosphere, agritourism, ecotourism, and lodging facility as well as environmental education programs to educate its customers on the skills and the merit of environmental protection. The activities offered by the farm cause fewer burdens on or even repair the environment. It is therefore an ideal subject for this study.

Our goal is to introduce customers' level of environmental education (EE) as a new determinant to improve TPB's predictability [3]. EE is essential to improve sustainability [9]. People with high EE are more likely to purchase greener products $[10,11]$. They actively seek out products or services that meet their needs for environmental protection, which in the case of this study is a farm stay.

The main aim of this study is therefore to investigate the causal relationship between an individual's EE and the TPB decision-making process that leads to the behavioral intention. The idea is that people with high EE are more likely to be attracted by the programs and activities offered by farm stays.

\subsection{Research Problem}

Based on the background, the research problem of this study is to understand whether people with higher level of EE are more likely to choose farm stays for their vacation. TPB is a model designed to answer all the above questions at once. The study uses Toucheng Leisure Farm in Taiwan as a case study to test the predictability of an expanded TPB model in anticipating behavioral intention. The proposed model is analyzed by structural equation modeling (SEM) via computer software called AMOS. Data for the study are collected in the farm stay.

\subsection{Research Purpose and Objectives}

The purpose of this study and the research questions are clearly stated in the previous section. In this section, the authors address the objectives that need to be completed in order to achieve the purpose. The few dimensions involved in the study include environmental education (EE), attitude (AT), subjective norm (SN), perceived behavioral control (BC), and future visit intention (FVI). The research objectives of this study are to (1) understand the direct causal impact of EE on individuals' $\mathrm{AT}, \mathrm{SN}$, and BC toward the farm stay and (2) understand the predictability of $\mathrm{AT}, \mathrm{SN}$, and $\mathrm{BC}$ on individuals' FVI to the farm stay.

\section{Literature Review}

\subsection{Environmental Education}

Environmental education is an important issue that receives a lot of attention since the 1960s. United Nations Educational, Scientific, and Cultural Organization (UNESCO) and other organizations have begun to advocate for EE-related programs and try to make them a part of public education. They attempt to increase worldwide awareness of environmental issues $[9,12]$ and hopefully slow down environmental degradation.

This is also the reason that most scholars address EE from an educationalist's point of view $[13,14]$. While this is completely justified, a sustainable entity must be concerned about both the environment and financial stability. An educationalist's perspective indoctrinates social responsibility and often overlooks the latter component, the financial stability. Sustainable management tries to reconcile the two sides (making profits and protecting the environment) of the same coin. Therefore, the goal is to provide eco-friendly products or services to customers and reduce the burden on the planet. Individuals with a high level of EE tend to seek out these products or services voluntarily [15]. 
EE is often measured by an individual's awareness of environmental problems, basic knowledge of environmental issues, attitude toward environmental protection, skills to implement them, and willingness or actual participation in environmental movements [16]. There are also other researchers [15] who proposed similar observations.

The concept of EE has been applied in the hospitality industry, such as visit intention to green hotels $[3,17,18]$. Farm stay is essentially another type of lodging service, which means that the concept should be applicable. Moreover, farm stays offer many activities specifically designed to target green customers, which means it is far more suitable than green hotels for the study of EE and behavioral intention.

\subsection{Theory of Planned Behavior}

TPB is proposed by Ajzen [1] as a research tool to study people's behavioral intention. The theory has been applied in many hospitality [7] and tourism studies [19]. The theory is traditionally a psychology theorem that postulates the causal linkages between beliefs and behavior. It is used to predict actions based on a reasoned decision-making process. TPB has a wide range of applicability including in the fields of advertising, public relations, advertising campaigns, and healthcare. Because TPB postulates that human behavior is based on a rational thinking process, some argue that it overlooks the emotional component [3]. Therefore, many researchers introduce additional components to improve its predictability [5]. Many argue that TPB should be expanded to adapt to the unique situation of a case $[3,5]$. This is because TPB assumes people are guided by a rational decision-making process, which is not usually the case. For example, many studies try to understand impulsive buying behavior [20]. Therefore, this study proposes that EE should be introduced to the TPB model to better understand the behavioral intention of green customers in regards to willingness to visit farm stays.

The theory comprises three pairs of determinants that affect an individual's behavioral intention. The first pair is behavioral belief and attitude. The idea is that an individual who believes a particular action has benefits for him/her will develop a positive attitude toward taking that action. The second pair of variables is normative beliefs and subjective norm. These variables are used to determine social influences on an individual's decision to take certain actions. The final pair is control belief and perceived behavioral control, which describes an individual's belief of his/her ability to overcome difficulties to perform an action. If all three pairs of determinants are positive, an individual is likely to have a high and positive level of behavioral intention. Although a behavioral intention is not necessarily an actual action [21], it still indicates that an individual is a potential contributor of the leisure farm in mountain regions. TPB is, therefore, a popular research tool to study the decision-making process.

\subsection{Future Visit Intention}

Future visit intention is a part of behavioral intention, which is a phrase that describes an individual's willingness to perform a particular behavior [1]. Behavioral intention is often used to study purchase intention [22] and visit intention [23]. There are also other studies that focus on other aspects of behavioral intentions that favor a company, such as more loyal customers [24], willingness to advocate [3], and willingness to pay more $[25,26]$. This paper incorporates all these elements of behavioral intention into future visit intention in the study.

\subsection{Research Framework and Hypotheses}

This study forms its theoretical framework building on past studies $[3,7,17,24]$ of customers' buying intentions of green products. Although some of them dealt with the concept of EE [3], few dealt with farm stays. This study proposes a research framework as shown in Figure 1 that describes the relationship of EE, TPB, and behavioral intention. The aim of the study is to prove that EE can help $\mathrm{TPB}$ to better predict green customers' behavioral intention regarding farm stays. 


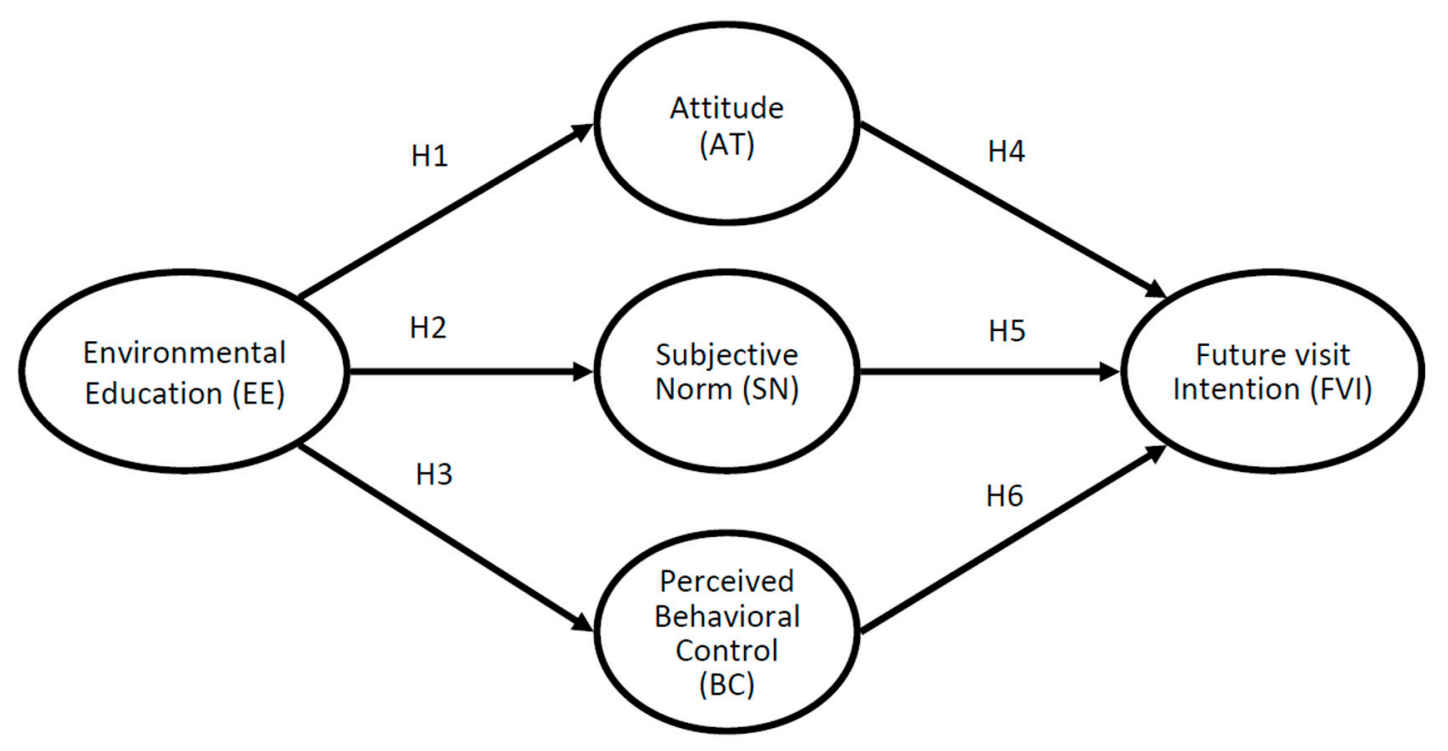

Figure 1. Research framework.

This study uses Toucheng Leisure Farm in Taiwan as an example to test the relationships between $\mathrm{EE}, \mathrm{TPB}$, and FVI. The corresponding hypotheses are stated below:

H1: Visitor with high EE is more likely to have positive AT,

$\mathrm{H} 2$ : Visitor with high $\mathrm{EE}$ is more likely to have positive $\mathrm{SN}$,

H3: Visitor with high EE is more likely to have positive BC,

H4: Visitor with high AT is more likely to have positive FVI,

H5: Visitor with high SN is more likely to have positive FVI, and

H6: Visitor with high $\mathrm{BC}$ is more likely to have positive FVI.

\section{Research Methodology}

\subsection{Locale of the Study}

The locale of the study was Toucheng Leisure Farm located in the mountain region in the northeast coast of Taiwan. A farm stay is specifically designed to offer greener products and services to its customers. Therefore, it is suitable for the aim of this study. The farm stay that this study examined offers many eco-friendly activities and accommodation.

Toucheng Leisure Farm offers one-day trips, two-day trips, environmental education programs, and other special activities and events. Customers are able to enjoy the farm environment, interact with animals, see the eco-life, and learn something about environmental protection. The farm stay also offers accommodation that can house 4-20 people at one time. There are forests, rivers, farms, fruit trees, and many rural elements that can be experienced while staying there. It was therefore an ideal research subject for the study.

\subsection{Sampling Method}

The study conducted a survey using questionnaires to collect data from the visitors of the farm stay. The visitors were given time to experience the farm stay before answering the questions. Interviewers were dispatched around the farm stay to collect as much data as possible within the given time frame. A convenient sampling method was used to survey the visitors of Toucheng Leisure Farm in Taiwan for data collection. Given that the intention of this study was to use structural equation modeling to analyze the data, 400 responses were needed [27]. To reduce the amount of missing data, face-to-face survey was conducted to ensure the usefulness of the questionnaires returned. 


\subsection{Measurement of Variables}

The questionnaire comprised the following sections. The first section was designed to collect sociodemographic information about the respondents and used either nominal or ordinal questions. The second part of the questionnaire was designed to assess respondents' EE level. These questions used a seven-point Likert scale where one indicated the lowest level and seven meant the highest level of EE. The third section was designed to assess respondents' future visit intention. Again, a seven-point scale was used in a similar fashion. The last section of the questionnaire comprised TPB dimensions namely AT, SN, and BC. They were also measured in the form of a seven-point scale.

The AT part of the questionnaire was meant to measure the perceived benefits customers received after visiting the farm stay. Therefore, this study referenced previous studies that focused on the benefit of agritourism. One study in Turkey [28] stated that agricultural experience, quality of life, relationship, adventure, and relaxation were the main gains of visiting a farm stay. Another study referenced was about segmentation by motivation for rural tourism activities in The Gambia [29]. In that study, experiencing a certain way of life, culture experiences, learning, and natural experiences were listed as the main contributors for people to visit a rural area. From these articles, we were able to develop six questions to measure respondents' level of AT.

For the $\mathrm{SN}$ and $\mathrm{BC}$ parts of questions, we reviewed items associated with interpersonal and structural constraint [30] issues one faced when trying to visit a place. We also referenced some papers using TPB to study people's willingness to stay in green hotels $[7,24]$ to develop these parts of the questionnaire. We then used six and seven items to measure respondents' level of SN and $\mathrm{BC}$, respectively.

\subsection{Pretesting of the Instrument}

The study planned to pretest the questionnaire in order to make sure the questions were understandable to the general population. The pretest was conducted at Toucheng Leisure Farm, Taiwan and among some university students. The sample size was around 100. Modifications were made according to the results of the pretest.

\subsection{Data Analysis}

This study used structural equation modeling (SEM) to analyze the data. There are a few pieces of software that offer this method of analysis. This study used AMOS, designed by the same company that develops SPSS. The study assessed the reliability of the data by examining composite reliability (CR) and average variance extracted (AVE) based on the assertion of Fornell et al. [31]. Model fit was also upheld by adhering to some of the indices: Goodness-of-fit index (GFI), comparative fit index (CFI), root mean square error of approximation (RMSEA), and $\chi 2 / \mathrm{df}[27,32]$.

\section{Results}

\subsection{Respondent Characteristics}

The survey was able to collect a total of 600 responses from the farm stay within the given duration. The sample comprises slightly more male $(52.3 \%)$ respondents than females $(47.7 \%)$. There were only $3 \%$ of the respondents below the age of 18 . This was partly due to the fact that younger respondents were less willing to participate in the survey. The majority of the respondents were 18-25 years old (39.5\%) and $26-40$ years old ( $44.2 \%)$, which together made up over $80 \%$ of the sample.

The majority of the sample held either a high school level education $(26 \%)$ or a university degree $(63.2 \%)$. These two groups together accounted for almost $90 \%$ of the sample. This is quite understandable in Taiwan, since university education is becoming very common.

As for occupation, most of the respondents were either white-collar workers $(32.5 \%)$ or students $(24.2 \%)$. There were also a substantial amount of respondents who were self-owned businessmen 
$(16 \%)$. The other major group was professionals (e.g., lawyers and accountants), which accounted for $12.7 \%$ of the sample.

As for family structure, $48.5 \%$ of the respondents were single, $22 \%$ were married, $27.2 \%$ were married with children, and $2 \%$ were divorced. Approximately half of the sample were married and the other half were single. Of the married respondents, three-fifth of them had children.

First time visitors made up $28.7 \%$ of the respondents, $25.5 \%$ were second time visitors, $31.8 \%$ were third time visitors, and $14 \%$ of the respondents had visited the farm more than four times.

As for the respondents' companions when visiting the farm, the majority of the respondents came with either family $(40.8 \%)$ or friends $(37.5 \%)$. About $10 \%$ of the respondents visited the farm with romantic partner or coworkers, each. Very few respondents came alone.

\subsection{Mean Score Analyses}

This section reports the findings of mean score analyses of items in the main constructs. The constructs involved in this study included: (1) Attitude, (2) subjective norm, (3) perceived behavioral control, and (4) future visit intention. The first three constructs belong to the model named the theory of planned behavior proposed by Ajzen [1]. The model proposed by this research is consistent with the study of Chang et al. [3].

There were three items in the attitude construct. The mean scores, ranged from 3.87 to 4.08 , which were all above the midpoint of the scale, three, suggesting a positive and favorable attitude toward the farm stay. The second part was the subjective norm, which comprised three items. The mean scores were between 3.49 and 3.79. These means were smaller than those of the attitudes. This suggests that social influence on respondents' decision to visit the farm stay was relatively smaller than that of their own. They were, however, still higher than the midpoint of scale. The next part was perceived behavioral control, which also comprised three items. The mean scores ranged from 3.90 to 4.09 . This suggests that the respondents believed that they could overcome the difficulties incurred when visiting the farm stay.

Finally, the future visit intention consisted of three items, which scored means ranging from 3.86 to 4.06. The information is listed in Table 1.

Table 1. Mean score analysis.

\begin{tabular}{llcc}
\hline Code & \multicolumn{1}{c}{ Description } & Mean & SD \\
\hline AT01 & I am very fond of the farm stay & 3.87 & 0.75 \\
AT02 & Coming to the farm stay is a right choice for my holiday & 4.08 & 0.75 \\
AT03 & The farm stay provides high quality experience & 4.07 & 0.77 \\
SN01 & My companions all support the visit to the farm stay & 3.79 & 0.84 \\
SN02 & People I know have high opinion about the farm stay & 3.68 & 0.86 \\
SN03 & The search on the Internet turns up some positive comment & 3.49 & 0.88 \\
BC01 & The farm stay is in the vicinity of my residence & 4.09 & 0.75 \\
BC02 & The farm stay is accessible to me & 3.90 & 0.81 \\
BC03 & The visit to the farm stay is affordable & 3.93 & 0.84 \\
FVI01 & I like to visit the farm stay again in the future & 4.06 & 0.70 \\
FVI02 & I am willing to pay a premium to support the environment & 4.03 & 0.72 \\
FVI03 & I will recommend my friends to visit the farm stay & 3.86 & 0.78 \\
\hline
\end{tabular}

Notes: AT—attitude; SN—subjective norm; BC—perceived behavioral control; FVI—future visit intention.

\subsection{Exploratory Factor Analysis (EFA) for Construct Validness}

The study used SPSS to conduct exploratory factor analysis (EFA) for the constructs of theory of planned behavior model. The theory divides the constructs into three aspects, namely, (1) attitude, (2) subjective norm, and (3) perceived behavioral control. The result of the EFA is presented in Table 2. The EFA allowed the study to examine whether the constructs were valid. Based on an eigenvalue greater than one as the threshold, the EFA divided the items into five constructs. Although it is different 
from the three constructs of theory of planned behavior, the grouping of the items was consistent with the proposed model.

Table 2. Exploratory factor analysis.

\begin{tabular}{ccccc}
\hline & $\mathbf{1}$ & $\mathbf{2}$ & $\mathbf{3}$ & $\mathbf{4}$ \\
\hline AT01 & & & 0.792 & \\
AT02 & & & 0.825 & \\
AT03 & & & 0.804 & \\
SN01 & 0.818 & & & \\
SN02 & 0.855 & & & \\
SN03 & 0.775 & & & 0.733 \\
BC01 & & & & 0.772 \\
BC02 & & & & \\
BC03 & & & & \\
\hline FVI01 & & 0.839 & & \\
FV102 & & 0.854 & & \\
FVI03 & & 0.786 & & \\
\hline Eigenvalue & 3.986 & 1.901 & & \\
\% Variance & 33.221 & 15.842 & 12.252 & 9.323 \\
Cumulative \% & 33.221 & 49.063 & 61.315 & 70.638 \\
\hline
\end{tabular}

Notes: Extraction—principal component; Rotation—varimax; five iterations

The factor loading of perceived behavioral control ranged from 0.733 to 0.827 . The factor loading of attitude ranged from 0.792 to 0.825 . The factor loading of subjective norm ranged from 0.775 to 0.855. The factor loading of future visit intention ranged from 0.786 to 0.854 . The eigenvalue of the four factors was 1.119 and explained a total of $70.638 \%$ of variance of the original items.

\subsection{Confirmatory Factor Analysis (CFA) for Model Goodness of Fit}

This study also used AMOS software to perform a structural equation modeling that functioned as a confirmatory factor analysis (CFA). The result is presented in Figure 2. The CFA model scored a $\chi^{2}$ of 338.683 and a degree of freedom (df) of 168 at a significance level of $p$ less than 0.000 . The $\chi 2 / d f$ ratio was 2.016, which is acceptable [32,33]. Model fit indices were also reported as follows. The GFI of the model was 0.949 , CFI was 0.964 , and RMSEA was 0.041 . These numbers fell within the suggested criteria of a good model fit [27,32].

The regression weights of the paths ranged from 0.66 to 0.88 , which indicated that the actual data fit the proposed model very well. The correlations between the constructs were less than 0.8 , which is a rule of thumb that indicates the factors isolate from each other quite well. The highest correlation was between perceived behavioral control and subjective norm, which was 0.57 . 


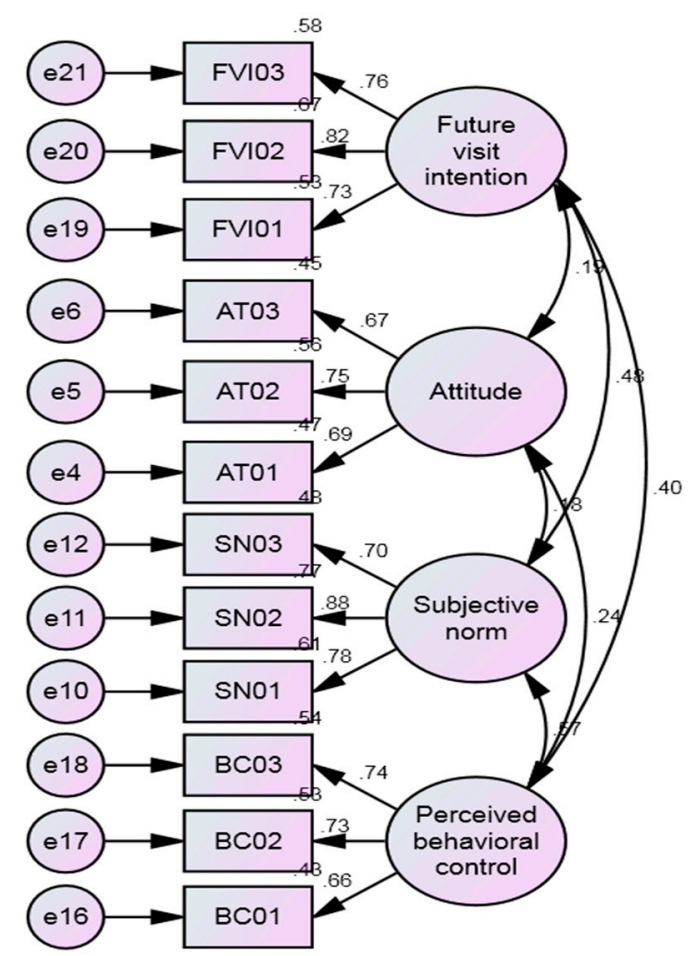

Figure 2. Confirmatory factor analysis.

\subsection{Composite Reliability and Discriminate Validity}

The data quality was examined by viewing indices such as composite reliability (CR), average variance extracted (AVE), maximum shared squared variance (MSV), and average shared square variance (ASV). Researchers [31] recommend, the CR value should exceed 0.6 and the AVE should be above 0.5 . As indicated in Table 3, only the AVE of attitude slightly failed that threshold. The MSV and ASV values were smaller than AVE values of all constructs. This indicated that the discriminate validity was also upheld.

Table 3. Data quality summary.

\begin{tabular}{ccccccccc}
\hline & CR & AVE & MSV & ASV & BC & AT & SN & FVI \\
\hline BC & 0.751 & 0.502 & 0.325 & 0.181 & 0.708 & & & \\
AT & 0.747 & 0.497 & 0.058 & 0.041 & 0.240 & 0.705 & & \\
SN & 0.830 & 0.622 & 0.325 & 0.194 & 0.570 & 0.176 & 0.789 & \\
FVI & 0.814 & 0.594 & 0.227 & 0.141 & 0.401 & 0.188 & 0.476 & 0.771 \\
\hline
\end{tabular}

Notes: CR—composite reliability; AVE—average variance extracted; MSV—maximum shared squared variance; ASV—average shared square variance; $\mathrm{BC}$ - perceived behavioral control; AT—attitude; SN—subjective norm; FVI-future visit intention.

The study used structural equation modeling (SEM) to analyze the data. In order to do this, the study also needed to examine indices associated with model fit. This was to make sure that the observed values were nicely fitted with the proposed model. According to researchers [27,32,34], the goodness-of-fit index (GFI) and comparative fit index (CFI) should exceed 0.7, root mean square error of approximation (RMSEA) should be less than 0.08 , and the ratio of chi-square and degree of freedom $(\chi 2 / \mathrm{df})$ should be less than 5 . The results were GFI $=0.920, \mathrm{CFI}=0.905$, RMSEA $=0.077$, and $\chi 2 / \mathrm{df}=4.576$. As indicated, all the criteria met the suggested thresholds. 


\subsection{Hypotheses Testing}

This study used AMOS to perform SEM to test the hypotheses. The result is presented in Figure 3 and Table 4. Hypotheses H1, H2, and H3 were proposed to describe the causal impact of environmental education on attitude, subjective norm, and perceived behavioral control.

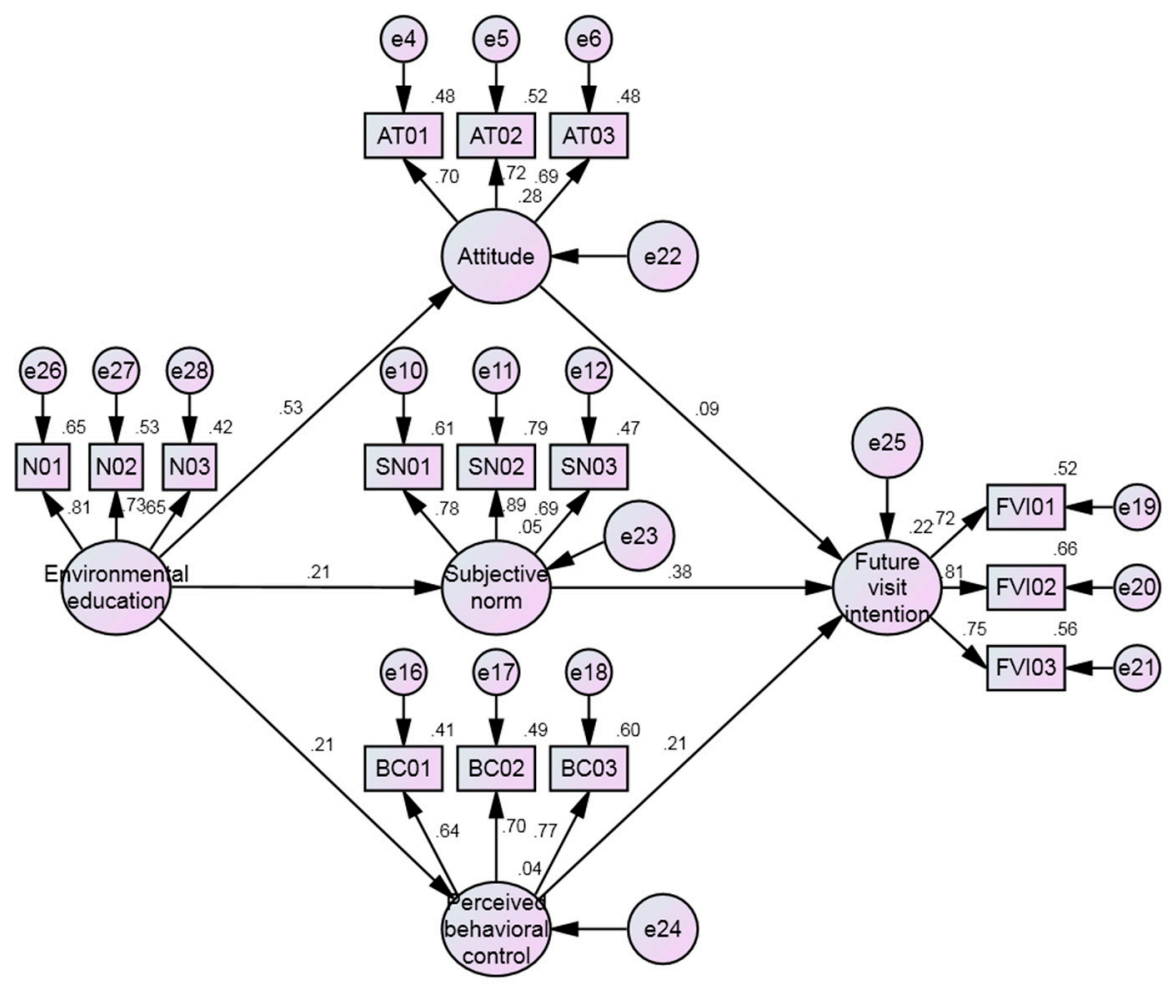

Figure 3. Model testing.

Table 4. Summary of results.

\begin{tabular}{ccccc}
\hline Hypotheses & Paths & Unstd. $\boldsymbol{\beta}$ & $\mathbf{p}$ & $\boldsymbol{\beta}$ \\
\hline H1 & $\mathrm{EE} \rightarrow \mathrm{AT}$ & 0.397 & $* * *$ & 0.53 \\
H2 & $\mathrm{EE} \rightarrow \mathrm{SN}$ & 0.2 & $* * *$ & 0.214 \\
$\mathrm{H} 3$ & $\mathrm{EE} \rightarrow \mathrm{BC}$ & 0.145 & $* * *$ & 0.21 \\
$\mathrm{H} 4$ & $\mathrm{AT} \rightarrow \mathrm{FVI}$ & 0.09 & 0.055 & 0.094 \\
H5 & $\mathrm{SN} \rightarrow \mathrm{FVI}$ & 0.293 & $* * *$ & 0.384 \\
H6 & $\mathrm{BC} \rightarrow \mathrm{FVI}$ & 0.217 & $* * *$ & 0.21 \\
\hline
\end{tabular}

Notes: ${ }^{* *}<0.001 ;$ EE-environmental education.

As indicated in Table 4, the path between environmental education and attitude was insignificant. The $\beta$ value of the path between environmental education and attitude was 0.53 with $p$ value less than 0.001 . The $\beta$ value of the path between environmental education and subjective norm was 0.214 with $p$ value less than 0.001 . The $\beta$ value of the path between environmental education and perceived behavioral control was 0.21 with $\mathrm{p}$ value less than 0.001 . These results indicated that hypotheses $\mathrm{H} 1$, $\mathrm{H} 2$, and $\mathrm{H} 3$ were supported by the data.

The $\beta$ value of the path between attitude and future visit intention was 0.094 with $p$ value equal to 0.055 , which is larger than 0.05 . The path was, therefore, not significant. The $\beta$ value of the path between subjective norm and future visit intention was 0.984 with $p$ value less than 0.001 . The $\beta$ value of the path between perceived behavioral control and future visit intention was 0.21 with $p$ value less than 0.001 . To sum up, hypothesis H4 was not supported, but hypotheses H5 and H6 were.

These results indicated that environmental education was able to foster respondents' decision-making behaviors that eventually lead to future visit intention. The attitude dimension, 
however, did not impact significantly on future visit intention. This indicated that respondents were generally influenced by external sources to decide whether or not to visit a farm stay. External sources, such as the approval of social groups or the removal of obstacles, could be a better way to convince people to purchase green products.

\section{Conclusions, Contribution, Implication, and Recommendation}

\subsection{Conclusions}

Based on the above results, the study compiled a summary of the findings in Table 5. Based on the results, one can see that seven of the nine hypotheses were accepted based on insignificant $\mathrm{p}$ values. The two rejected hypotheses were both associated with control belief. This finding suggests that environmental education made an individual more pro-environmental and susceptible to the social norms about environmental protection. Environmental education, however, did not affect the inconvenience or higher cost incurred by purchasing green products.

Table 5. Summary of hypotheses.

\begin{tabular}{ccccccc}
\hline \multicolumn{2}{c}{ Cause } & & Effect & & $\beta$ & Result \\
\hline H1 & Environmental education & $\rightarrow$ & Attitude & 0.530 & $* * *$ & Supported \\
H2 & Environmental education & $\rightarrow$ & Subjective norm & 0.214 & $* * *$ & Supported \\
H3 & Environmental education & $\rightarrow$ & Perceived behavioral control & 0.210 & $* * *$ & Supported \\
H4 & Attitude & $\rightarrow$ & Future visit intention & 0.094 & Rejected \\
H5 & Subjective norm & $\rightarrow$ & Future visit intention & 0.384 & $* * *$ & Supported \\
H6 & Perceived behavioral control & $\rightarrow$ & Future visit intention & 0.210 & $* * *$ & Supported \\
\hline & \multicolumn{2}{c}{ Notes: ${ }^{* * *} \mathrm{p}<0.001$} & & &
\end{tabular}

Environmental education possesses a higher impact on normative belief than on behavioral belief. This suggests that, at least for now, the respondents are motivated by social reasons to purchase green products more than for their own environmental consciousness. This also suggests that the environmental education is still at its infancy.

However, attitude possesses higher impact on future visit intention than subjective norm. This means in the end, personal attitude is the determining factor for people's green behavior. Therefore, it is possible to use environmental education to slowly increase an individual's subjective norms, which hopefully eventually affect their attitude through social norms.

\subsection{Theoretical Contribution}

TPB model consists of three sets of beliefs, each leads to an antecedent of behavioral intention. The first one is behavioral belief, which refers to one's belief that an action can be beneficial for them in a meaningful way. They then develop a positive attitude toward taking the action. The second one is called normative belief, which is an individual's belief about his family, friends, and social circle's opinion about the action. If his or her social circle is supportive about the action, he or she is more likely to take it. The final one is called control beliefs, which are the difficulties an individual faced when they try to perform an action. If the difficulties are manageable, they will then take the action.

Based on the above TPB theory, the contribution of this study was to introduce customers' level of environmental education (EE) as a new determinant to improve TPB's predictability [3]. EE is essential to improve sustainability [9]. People with high EE are more likely to purchase greener products $[10,11]$. The other contribution of this study was to verify the causal relationship between an individual's EE and his/her TPB decision-making process that leads to behavioral intention. This study confirmed that people with high EE were more likely to be attracted by the programs and activities offered by farm stays. 


\subsection{Managerial Implication}

The findings of the study were based on an eco-friendly farm stay named Toucheng Leisure Farm in Taiwan. The findings suggest that environmental education has positive and significant impacts on behavioral belief and normative belief, which subsequently leads to positive attitude and subjective norm, respectively. Attitude, subjective norm, and perceived behavioral control all have a positive impact on future visit intention.

For a farm stay, slowly raising awareness regarding environmental education is a good thing. It can give potential customers an incentive to purchase green products, thereby boosting their possibility of visiting again. The respondents acknowledged the fact that purchasing green products could cause some level of inconvenience and incur additional cost while travelling. That did not seem to affect their perceived behavioral control. This means that they were willing to accept those inconveniences in the name of environmental protection.

Farm stay managers can design more environmental education programs to increase the awareness of environmental protection issues. By doing so, they will be effectively increasing the pool of their potential customers. These customers, as the findings demonstrated, are more willing to revisit and purchase at a premium price. Therefore, in the long run, devoting in environmental education can be beneficial for business enterprises.

For government agencies and nonprofit organizations that aim for environmental protection, it is recommended to work with farm stays to promote environmental education. This way, farm stays can provide their customers with accurate environmental knowledge and training of environmental protection skills. For government and other organizations, farm stay is an effective medium to reach the public and promote the ideal of environmental protection.

\subsection{Recommendation to Future Research}

There are various practical constraints due to the limitation of this study. For most studies, time and financial constraints are amongst the common constraints. This study was the same. This study was required to finish in a given time. Therefore, a lot of things needed to be done in a relatively short amount of time. There was also the constraint introduced by the design of the research method. These constraints serve as a suggestion for future research.

Due to the financial and time limitation, this study was only able to conduct a survey in one farm stay. The future study can apply the questionnaire of this study in other farm stays, even better if it can apply to cases in other countries. Future study then can compare the results or even do a comparative study. This will allow a study to test and see whether different farm stays present different results.

This study used Toucheng Leisure Farm in the mountain region of Taiwan as a case study. It remains unclear what the validity of the findings for larger communities is. Therefore, this study recommends that the community-based tourism can be used as another case study to verify the validity of the findings for larger communities.

Environmental education shows no significant impact on control belief, which has no significant impact on perceived behavioral control. This suggests that the theory of planned behavior is not always applicable to all cases. It will be interesting to see if the theory of planned behavior can be applied to other sectors of the lodging industry.

Author Contributions: Conceptualization, W.L., S.-Y.H., W.T., C.C. and F.-M.C.; methodology, W.L., S.-Y.H., W.T., C.C. and F.-M.C.; software, S.-Y.H., and F.-M.C.; validation, W.L., S.-Y.H., W.T., C.C. and F.-M.C.; formal analysis, S.-Y.H., W.T. and F.-M.C.; investigation, F.-M.C.; resources, F.-M.C.; data curation, F.-M.C.; writing-original draft preparation, W.L., S.-Y.H., W.T., C.C. and F.-M.C.; writing-review and editing, W.L., S.-Y.H., W.T., C.C. and F.-M.C.; visualization, W.L.; supervision, W.T., C.C. and F.-M.C.; project administration, W.T. and C.C.; funding acquisition, W.T. and C.C.

Funding: This study was supported by grants from the research funding of Maejo University in Thailand, the Philosophy and Social Science foundation of universities in Jiangsu (2018SJA1833), and the Ministry of Culture and Tourism Project (WMYC20183-186); Changzhou Institute of Industry Technology Project (YB201813101007) \& (HKRW2018-38). 
Acknowledgments: The authors would like to thank Maejo University, Philosophy and Social Science foundation of universities in Jiangsu, China Ministry of Culture and Tourism, and Changzhou Institute of Industry Technology for their funding supports as well as three anonymous reviewers of the Journal for the valuable comments.

Conflicts of Interest: The authors declare no conflict of interest.

\section{References}

1. Chan, E.S.W. Barriers to EMS in the hotel industry. Int. J. Hosp. Manag. 2008, 27, 187-196. [CrossRef]

2. Best, M.N.; Thapa, B. Motives, facilitators and constraints of environmental management in the Caribbean accommodations sector. J. Clean. Prod. 2013, 52, 165-175. [CrossRef]

3. Chang, L.-H.; Tsai, C.-H.; Yeh, S.-S. Evaluation of Green Hotel Guests' Behavioral Intention; Chen, J.S., Ed.; Emerald Group Publishing Limited: Bingley, UK, 2014; Volume 10, pp. 75-89.

4. Rennings, K. Redefining innovation-Eco-innovation research and the contribution from ecological economics. Ecol. Econ. 2000, 32, 319-332. [CrossRef]

5. Han, H.; Hsu, L.-T.J.; Lee, J.-S.; Sheu, C. Are lodging customers ready to go green? An examination of attitudes, demographics, and eco-friendly intentions. Int. J. Hosp. Manag. 2011, 30, 345-355. [CrossRef]

6. Ajzen, I. The theory of planned behavior. Organ. Behav. Hum. Decis. Process. 1991, 50, 179-211. [CrossRef]

7. Han, H.; Hsu, L.T.; Sheu, C. Application of the theory of planned behavior to green hotel choice: Testing the effect of environmental friendly activities. Tour. Manag. 2010, 31, 325-334. [CrossRef]

8. Han, H.; Kim, Y. An investigation of green hotel customers' decision formation: Developing an extended model of the theory of planned behavior. Int. J. Hosp. Manag. 2010, 29, 659-668. [CrossRef]

9. Kopnina, H. Revisiting education for sustainable development (ESD): Examining anthropocentric bias through the transition of environmental education to ESD. Sustain. Dev. 2011, 22, 73-83. [CrossRef]

10. Ko, E.; Hwang, Y.K.; Kim, E.Y. Green marketing' functions in building corporate image in the retail setting. J. Bus. Res. 2013, 66, 1709-1715. [CrossRef]

11. Badulescu, D.; Badulescu, A.; Bac, D.P.; Saveanu, T.; Florea, A.; Perticas, D. Education and Sustainable Development: From Theoretical interest to specific behaviours. J. Environ. Prot. Ecol. 2017, 18, 1698-1705.

12. Leonidou, L.; Leonidou, C.; Kvasova, O. Antecedents and Outcomes of Consumer Environmentally-Friendly Attitudes and Behavior. J. Mark. Manag. 2010, 26, 1319-1344. [CrossRef]

13. Bell, D.R. Creating green citizens? Political liberalism and environmental education. J. Philos. Educ. 2004, 38, 37-54. [CrossRef]

14. Morgan, S.C.; Hamilton, S.L.; Bentley, M.L.; Myrie, S. Environmental education in botanic gardens: Exploring brooklyn botanic garden's project green reach. J. Environ. Educ. 2009, 40, 35-52. [CrossRef]

15. Kollmuss, A.; Agyeman, J. Mind the gap: Why do people act environmentally and what are the barriers to pro-environmental behavior? Environ. Educ. Res. 2002, 8, 239-260. [CrossRef]

16. Stapp, W.B.; Bennett, D.; Bryan, W.; Fulton, J.; MacGregor, J.; Nowak, P.; Havlick, S. The concept of environmental education. J. Environ. Educ. 1969, 1, 30-31. [CrossRef]

17. Yeh, S.-S.; Ma, T.; Huan, T.C. Building social entrepreneurship for the hotel industry by promoting environmental education. International J. Contemp. Hosp. Manag. 2016, 28, 1204-1224. [CrossRef]

18. Pan, S.-L.; Chou, J.; Morrison, A.M.; Huang, W.-S.; Lin, M.-C. Will the Future Be Greener? The Environmental Behavioral Intentions of University Tourism Students. Sustainability 2018, 10, 634. [CrossRef]

19. Hsu, C.H.C.; Huang, S.S. An extension of the theory of planned behavior model for tourists. J. Hosp. Tour. Res. 2012, 36, 390-417. [CrossRef]

20. Liang, Y.-P. The Relationship between Consumer Product Involvement, Product Knowledge and Impulsive Buying Behavior. Procedia Soc. Behav. Sci. 2012, 57, 325-330. [CrossRef]

21. McKercher, B.; Tony, S.M. Is intention to return a valid proxy for actual repeat visitation? J. Travel Res. 2012, 51, 671-686. [CrossRef]

22. Kim, Y.J.; Njite, D.; Hancer, M. Anticipated emotion in consumers' intentions to select eco-friendly restaurants: Augmenting the theory of planned behavior. Int. J. Hosp. Manag. 2013, 34, 255-262. [CrossRef]

23. Chen, M.-F.; Tung, P.-J. Developing an extended Theory of Planned Behavior model to predict consumers' intention to visit green hotels. Int. J. Hosp. Manag. 2014, 36, 221-230. [CrossRef]

24. Han, H. Travelers' pro-environmental behavior in a green lodging context: Converging value-belief-norm theory and the theory of planned behavior. Tour. Manag. 2015, 47, 164-177. [CrossRef] 
25. Kuminoff, N.V.; Zhang, C.; Rudi, J. Are travelers willing to pay a premium to stay at a "green" hotel? Evidence from an internal meta-analysis of hedonic price premia. Agric. Resour. Econ. Rev. 2010, $39,468$. [CrossRef]

26. Roe, B.; Teisl, M.F.; Levy, A.; Russell, M. US consumers' willingness to pay for green electricity. Energy Policy 2001, 29, 917-925. [CrossRef]

27. Hair, J.F.; Black, W.C.; Babin, B.J.; Anderson, R.E. Multivariate Data Analysis, 7th ed.; Prentice Hall: Englewood Cliffs, NJ, USA, 2009.

28. Artuger, S.; Kendir, H. Agritourist motivations: The case of Turkey. Int. J. Bus. Manag. 2013, 8, 63-69. [CrossRef]

29. Rid, W.; Ezeuduji, I.O.; Pröbstl-Haider, U. Segmentation by motivation for rural tourism activities in The Gambia. Tour. Manag. 2014, 40, 102-116. [CrossRef]

30. Vassiliadis, C.A.; Priporas, C.-V.; Andronikidis, A. An analysis of visitor behaviour using time blocks: A study of ski destinations in Greece. Tour. Manag. 2013, 34, 61-70. [CrossRef]

31. Fornell, C.; Larcker, D.F. Structural equation models with unobservable variables and measurement error: Algebra and statistics. J. Mark. Res. 1981, 18, 382-388. [CrossRef]

32. Hooper, D.; Coughlan, J.; Mullen, M. Structural equation modelling: Guidelines for determining model fit. The Electronic J. Bus. Methods 2008, 6, 53-60. [CrossRef]

33. Bearden, W.O.; Sharma, S.; Teel, J.E. Sample size effects on chi square and other statistics used in evaluating causal models. J. Mark. Res. 1982, 19, 425-430. [CrossRef]

34. Kline, R.B. Principles and Practice of Structural Equation Modeling; Guilford Press: New York, NY, USA, 2011.

(C) 2019 by the authors. Licensee MDPI, Basel, Switzerland. This article is an open access article distributed under the terms and conditions of the Creative Commons Attribution (CC BY) license (http://creativecommons.org/licenses/by/4.0/). 